\title{
Evaluation of Field Level Adaptation Measures Under the Climate Change Scenarios in Rice Based Cropping System in India
}

\author{
Y. A. Rajwade $^{1}$ - D. K. Swain ${ }^{1}$ - K. N. Tiwari $^{1}$ • \\ U. C. Mohanty ${ }^{2}$ P. Goswami ${ }^{3}$
}

Received: 27 April 2015 /Accepted: 11 October 2015 / Published online: 23 October 2015

(C) Springer International Publishing Switzerland 2015

\begin{abstract}
With the rise in population, under future scenarios, global food demand is expected to increase. Biotic and abiotic factors such as climate change are threat to food security owing to its variability, occurrence, duration and magnitude of extreme events. Since, the climate change is unequivocal, the adaptations and mitigations for sustainable agricultural production can minimize its negative impact on agriculture and improve food grain productivity. The grain yield of rice and peanut was simulated for the base period (1969-1999) and future periods 2020 (2011-2040), 2050 (2041-2070) and 2080 (20712100) under A2 and B2 scenarios of HadCM3 Global Climate Model. Under the A2 and B2 scenarios, the yield of both rice and peanut declined from base period to the future periods 2011-2040, 2041-2070 and 2071-2100. The cultivar 'IR 36' was found to be more sensitive to rising temperature under future climate scenarios as compared to 'Swarna.' The yield decline for future climate scenarios increased with locations from higher (Kharagpur and Cuttack) to lower latitude (East Godavari and Vizianagaram). Earlier transplanting time of rice compared to normal (15 July) and sowing time of peanut from normal (9 February) increased the simulated yields of rice-peanut system at higher latitude and reduced the yield loss at lower latitude in future climate scenarios. Delayed planting caused maximum grain yield reduction of the cropping system in future climate scenarios at all the locations.
\end{abstract}

D. K. Swain

swain@agfe.iitkgp.ernet.in

1 Agricultural and Food Engineering Department, Indian Institute of Technology Kharagpur, Kharagpur 721302, India

2 School of Earth Ocean and Climate Sciences, Indian Institute of Technology Bhubaneswar, Bhubaneswar 751013, India

3 CSIR Centre for Mathematical Modelling and Computer Simulation (C-MMACS), NAL Belur Campus, Bangalore 560037, India 
Keywords Adaptation $\cdot$ Climate change $\cdot$ Crop model $\cdot$ Rice-peanut cropping system $\cdot$ Subtropical India

\section{Introduction}

The global demand for food is rising day by day with the increase in population and dietary factors. The current world population of 6.9 billion is expected to rise to 8.3 and 9.1 billion by 2030 and 2050, respectively. To meet this demand, the global food production is required to be increased over $40 \%$ by 2030 and $70 \%$ by 2050 (FAO 2009). About $70 \%$ of the world's staple food is produced from rainfed area which is $82 \%$ of the world's cropland area (Sharma 2011). Rice is the second most important staple food in the world after wheat, with annual production of $456 \mathrm{Mt}$. About $90 \%$ of world rice yield is produced and consumed in Asia-Pacific (http:// www.fao.org/docrep/003/x6905e/x6905e04.html). Rice grain production in India is $104 \mathrm{Mt}$ which makes $22.8 \%$ of world rice production. Of the total rice area of $44 \mathrm{Mha}, 55 \%$ is under rainfed ecosystem that contributes $39 \%$ of rice production in India (Vittal et al. 2004). Considering the expected population rise in India to 1.6 billion by 2050 from the present 1 . 1 billion, the food grain production needs to be increased through increasing productivity of rainfed agro-ecosystem (Aggarwal et al. 2008). Although there is need of production and productivity improvement, the major constraints of rainfed ecosystems, such as low soil fertility due to imbalanced use of chemical fertilizers, uneven distribution of rainfall, drought and submergence during critical periods, etc., threaten food security at national and global level. In addition to this, the global mean temperature at the end of 21 st century is expected to increase over $1.5^{\circ} \mathrm{C}$ compared to 1850 to 1900 for all RCP scenarios except for RCP 2.6 with non-uniform increase over the different regions (IPCC 2013), is expected to have substantial impact on food grain production of developing countries located in tropical and sub-tropical latitude (Parry et al. 2004; Mall et al. 2006).

Under the climate change scenarios, plant response to elevated $\mathrm{CO}_{2}$ alone without change in temperature and precipitation was found to be positive, which will directly depend on photosynthesis pathway of plant, species, water and nutrient availability. Rice being a C3 crop, its photosynthesis, yield and biomass are expected to increase under elevated $\mathrm{CO}_{2}$ in absence of temperature increase (Kim et al. 2003; Ainsworth and Long 2005; Razzaque et al. 2011; Madan et al. 2012). But under the elevated $\mathrm{CO}_{2}$ and temperature, the positive effect of $\mathrm{CO}_{2}$ will be nullified by temperature rise (Sheehy et al. 2006; Krishnan et al. 2007). Thus, climate change and its impact is a major constraint in cultivation of rice crop by farmers, and therefore, adaptations based on future simulated grain yields can provide valuable inputs to sustain the yield.

The crop production is affected by large numbers of variables and interactions among them, thus being a very complex system. Conducting field trials to explain all their effects becomes increasingly complex. A number of crop growth models have been developed (Kropff et al. 1994; Jones et al. 2003; Aggarwal et al. 2006a, b) and used as decision support systems for management recommendations and to explore the effects of climatic change on crop yield and evaluate agro-adaptations (Bouman et al. 1996; Jones et al. 2003; Trnka et al. 2004; Xiong et al. 2007; Silva et al. 2007).

The CERESRice (Crop Environment Resource Synthesis) and CROPGRO of DSSAT v4.5 (Decision Support System for Agro-Technology Transfer) are process-oriented, managementlevel models of rice and peanut crop growth and development, respectively (Jones et al. 2003), 
which can be used to simulate the phenology, crop growth and yield and biomass partitioning of these plants. The simulation processes of both models are dynamic, mechanistic and process based, which are affected by environmental and cultivar specific factors.

Many researchers have used DSSAT for analysis of climate change impacts on rice-based production system in India (Subash and Ram Mohan 2012; Mishra et al. 2013). Satapathy et al. (2014) simulated the possible climate change impacts using HadCM3 data and found a continuous decline in the rice grain yield for the years 2020, 2050 and 2080 with increasing temperature $>0.8{ }^{\circ} \mathrm{C}$. Swain and Thomas (2010) reported 7 to $27 \%$ decline in rice yield under GCM (Global Climate Model) scenarios at different locations in India. Decline in rice yield in India under future climate scenarios has also been reported by earlier researchers (Pathak et al. 2003; Krishnan et al. 2007).

The adverse impact of climate change on rice-based production systems could be minimized through location specific adaptations on cultivar selection, planting time, land management etc. Few studies have been attempted to assess the vulnerability of cropping systems under projected climate change scenarios under rainfed ecosystem in India, but lacking with location specific adaptations and recommendations. There is a need to analyze the impact of future climate on rice-based rainfed production systems and evaluate agro-adaptations, which can be implemented at field level. The present investigation was carried out to assess the impact of climate change on rice-peanut cropping systems using crop simulation technique and to evaluate potential of cultivars and planting times as adaptation measures to four locations in eastern India.

\section{Materials and Methods}

\subsection{Experimental Site}

Field experiments for calibration and testing of CERES model for rice and CROPGRO model for peanut were carried out in the research farm of Agricultural and Food Engineering Department, Indian Institute of Technology Kharagpur, Kharagpur $\left(22^{\circ} 19^{\prime} \mathrm{N}\right.$ latitude and $87^{\circ} 19^{\prime}$ E longitude), India. Soil of the location is acid lateritic with sandy loam in texture. The climate of Kharagpur is classified as humid and subtropical. It is characterized as hot and humid in the summer (April and May), rainy during June to September, moderately hot and dry in autumn (October and November), cool and dry in winter (December and January) and moderate in spring (February and March). The site receives an average annual rainfall of $1400 \mathrm{~mm}$ with an occurrence of $70-75 \%$ of the total rainfall in the monsoon months (June to October). The average daily temperature varies between $21^{\circ} \mathrm{C}$ in December/January and $32^{\circ} \mathrm{C}$ in May/June.

\subsection{Experimental Details}

For calibration and testing of CERESRice model, two popular rice varieties, 'IR 36' and 'Swarna,' with growing periods of 120 and 150 days, respectively, were cultivated at their recommended fertilizer levels during the wet season (June-November) of the years 2010 and 2011. The recommended fertilizer levels for IR 36 and Swarna were 100:50:60 and 120:50:60 kg ha ${ }^{-1}$, respectively, of $\mathrm{N}: \mathrm{P}_{2} \mathrm{O}_{5}: \mathrm{K}_{2} \mathrm{O}$, while for peanut the recommended dose was 30:60:50. For calibration and testing of CROPGRO model, a single popular peanut 
cultivar 'AK12-24' of growing duration of 110 days was cultivated at recommended fertilizer levels during the dry season (February-May) of the years 2011 and 2012.

The crop data on appearance of phenological events, time series above ground biomass, yield components and yield of the crops of the first year were used for calibration and of the second year for testing of the model parameters. These genetic coefficients of CERESRice and CROPGRO are mainly based on duration of vegetative growth, photoperiod sensitivity, time from flowering to maturity, unit seed weight, biomass partitioning, temperature tolerance etc.

\subsection{Model Calibration and Testing}

Crop growth in CERESRice and CROPGRO is simulated by employing a carbon balance approach in a source-sink system (Ritchie et al. 1998). Genetic coefficients of the models were estimated through calibration and evaluation process. The genetic coefficients for rice (cv. IR 36 and Swarna) and peanut (cv. AK 12-24) were calibrated using experimental data on phenology, biomass and economic yield. Statistical methods were selected to compare the results from simulations and observations. Model performance was evaluated using the statistical parameters such as Normalized Root Mean Squared Error (RMSEn) and D-index (Willmott et al. 1985) as common tools to test the goodness-of-fit of simulation models as given in Eqs. (1) and (2):

$$
\begin{gathered}
\text { RMSEn }=\frac{\left\{\sum_{i=1}^{n} \frac{\left(S_{i}-O_{i}\right)^{2}}{n}\right\}^{0.5}}{\overline{O_{\text {avg }}}} \\
D-\text { index }=1-\frac{\sum_{i=1}^{n}\left(S_{i}-O_{i}\right)^{2}}{\sum_{i=1}^{n}\left(\left|S_{i}-\overline{O_{\text {avg }}}\right|+\left|O_{b i}-\overline{O_{\text {avg }}}\right|\right)^{2}}
\end{gathered}
$$

where, $\mathrm{S}_{\mathrm{i}}$ and $\mathrm{O}_{\mathrm{i}}$ are the model simulated and experimentally measured points, respectively, $\overline{O_{\text {avg }}}$ is the average of observed values, and $\mathrm{n}$ is the number of observations.

\subsection{Climate Change Scenarios Used for Crop Yield Simulation}

Daily maximum and minimum temperatures, rainfall and solar radiation are the minimum data requirements for the DSSAT model. The daily weather data for the base period (1969-1999) was used for the past yield simulation and future weather from HadCM3 of Global Climate Model (GCM) downscaled data for the nearest grid of the specific locations was used for forecasting the crop yield for future climate scenarios. The HadCM3 model couples an atmospheric GCM with an ocean GCM. The major advantage is the need of additional artificial heat and freshwater fluxes at the ocean surface is eliminated as the high ocean resolution of HadCM3 serves the purpose (Gordon et al. 2000; Pope et al. 2000). The forecasted data was downscaled for A2 and B2 SRES (Special Report on Emission Scenarios) scenarios. 
The A2 scenario represents very heterogeneous world in which economic development, technology are fragmented and considered at regional level with continuously increasing population. The B2 scenario family describes a world in which the emphasis is on local solutions to economic, social, and environmental sustainability. The output from the HadCM3 model for SRES A2 and B2 was used as input to crop models of DSSAT for yield simulation at four locations namely, Kharagpur, Cuttack, East Godavari and Vizianagaram of Eastern India. The crop yield was simulated using future weather data for the periods 2011-2040, 2041-2070, and 2071-2100 of A2 and B2 scenarios for all the locations and the change in the yield was compared with the base-line (1969-1999) yield. The $\mathrm{CO}_{2}$ levels for base period (1969-99), 2020 (20112040), 2050 (2041-2070) and 2080 (2071-2100) were taken as 380, 420, 480, and 540 ppm, respectively. The increment in temperature over the base period at different locations is shown in Fig. 1. The soil properties and basic weather parameters of the locations are given in Table 1 .

\subsection{Yield Simulation for Rice-Peanut Cropping System}

The yield of rice-peanut cropping system was simulated for past and future weather at all the selected locations. As rice is the main crop in the system, two rice cultivars were chosen in the simulation process for understanding their adaptability to climate change under rainfed ecosystem. The rice cultivars were 'IR 36' of medium duration (120 days) type and 'Swarna' of long duration (150 days) type. The cropping system of peanut with the Medium-duration rice cultivar is named as MP and with long-duration rice cultivar is named as LP.

The simulated yield of the cropping systems was calculated in terms of rice equivalent yield using Eq. (3).

$$
\text { Rice eq.yield }=Y_{R}+\frac{Y_{P} \times P_{P}}{P_{R}}
$$

where, Rice eq. Yield is the rice equivalent yield of the system $\left[\mathrm{kg} \mathrm{ha}^{-1}\right], \mathrm{Y}_{\mathrm{R}}$ is the yield of rice $\left[\mathrm{kg} \mathrm{ha}^{-1}\right], \mathrm{Y}_{\mathrm{P}}$ is the yield of peanut $\left[\mathrm{kg} \mathrm{ha}^{-1}\right], \mathrm{P}_{\mathrm{P}}$ is the minimum support price of peanut as per Govt. of India for the year 2013, and $P_{R}$ is the minimum support price of rice as per Govt. of India for the year 2013.

The minimum support price for rice and peanut was taken as Rs. 13.1 and Rs. 40.0 per kg, respectively (http://agricoop.nic.in/imagedefault/whatsnew/latestmsp.pdf). The percentage

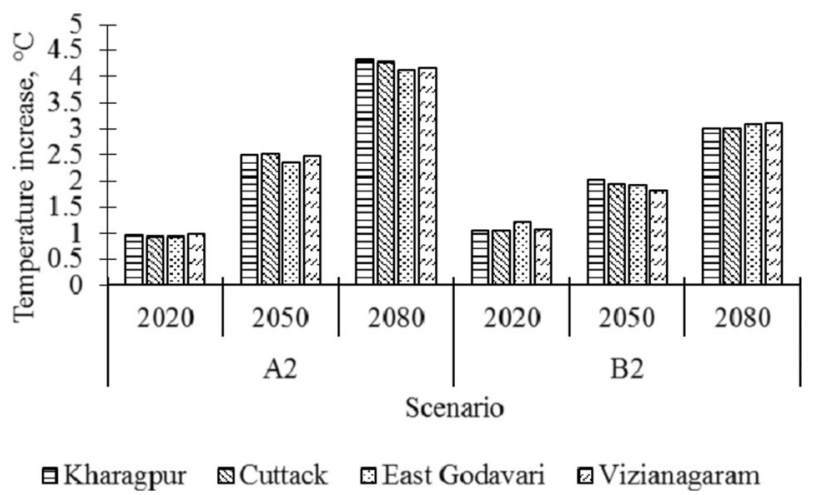

Fig. 1 Daily average temperature increase for the years 2020, 2050 and 2080 under A2 and B2 scenarios of climate change of HadCM3 as compared to base period at different location in India 


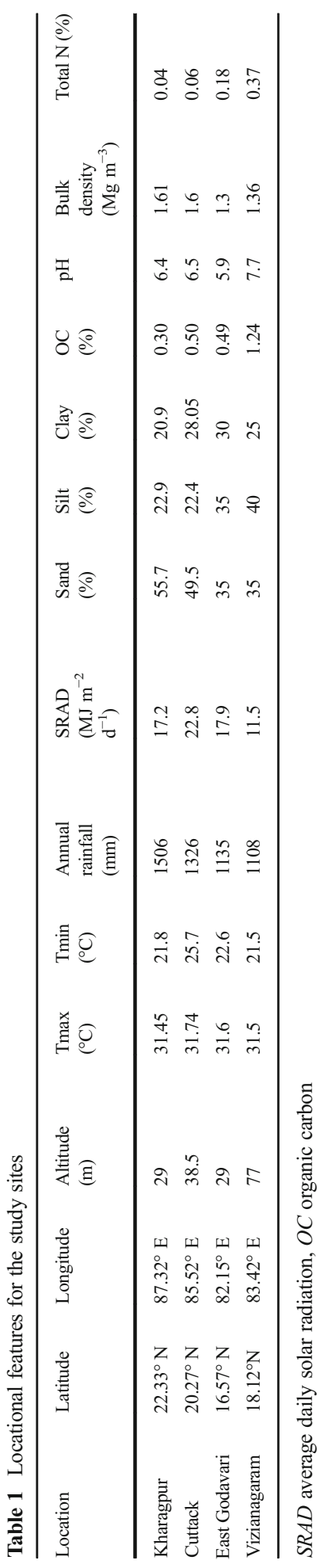


change in the yield of cropping system under future scenario as compared to base period yield was calculated using Eq. (4):

$$
\text { Percentage change in the yield of cropping system }=\frac{Y_{C C}-Y_{b}}{Y_{b}} \times 100
$$

where, $\mathrm{Y}_{\mathrm{cc}}$ is the average yield under climate change scenario $\left[\mathrm{kg} \mathrm{ha}^{-1}\right], \mathrm{Y}_{\mathrm{b}}$ is the average yield under base period $\left[\mathrm{kg} \mathrm{ha}^{-1}\right]$.

\subsection{Evaluation of Adaptation Measures}

Many cropping practices have been recommended as to mitigate the impact of climate change as farm level adaptations. The most commonly evaluated adaptation measures are adjustment of sowing date, cropping pattern, use of high yielding varieties and also use of temperature tolerant varieties in crop production system (Rosenzweig and Hillel 1998; Ogden and Innes 2008).

In the present study, planting date and varietal adaption were evaluated for all the locations. The yield was simulated for the five planting dates each for rice and peanut. For the rice, the planting dates were 1 June, 15 June, 30 June, 15 July and 31 July. The sowing dates for peanut were 26 December, 9 January, 24 January, 9 February and 24 February. The current planting dates for rice and peanut are 15 July and 9 February.

To evaluate planting date as an adaptation measure, the percentage change in the yield under the different planting dates was determined by comparing with the yield under the current planting date as given in Eq. (5).

$$
\text { Percentage change in the yield of cropping system }=\frac{\mathrm{Y}_{\mathrm{P}}-\mathrm{Y}_{C P}}{\mathrm{Y}_{C P}} \times 100
$$

where, $\mathrm{Y}_{\mathrm{P}}$ is the average yield under the given planting date $\left[\mathrm{kg} \mathrm{ha}^{-1}\right]$, and $\mathrm{Y}_{\mathrm{CP}}$ is the average yield under the current planting date $\left[\mathrm{kg} \mathrm{ha}^{-1}\right]$.

\section{Results and Discussion}

\subsection{Model Calibration and Testing}

\subsubsection{Rice}

The CERESRice model was calibrated and validated for the medium-duration cultivar 'IR 36' and long-duration cultivar 'Swarna' using wet season data of the years 2010 and 2011, respectively. During calibration, the RMSEn and D-index between simulated and observed values of top (above ground) biomass were 0.27 and 0.978 , respectively for IR 36 , and 0.30 and 0.966 , respectively for Swarna. The observed and simulated values for anthesis and maturity days were in close match ( \pm 3 days) and the difference between simulated and observed yield was less than $2 \%$. The calibrated genotype coefficients of both cultivars are given in Table 2. The genotype coefficients P1 and P2R are higher in Swarna as compared to IR 36 because of the longer vegetative period of the former cultivar as compared to the later. During testing (Fig. 2), there was close match between simulated and observed top biomass of 
Table 2 Calibrated genotype coefficients of CERES-Rice model for the cultivars 'IR 36' and 'Swarna'

\begin{tabular}{llll}
\hline Coefficient & Description/Unit & IR 36 & Swarna \\
\hline P1 & Basic vegetative phase, ${ }^{\circ}$ C-days & 470.0 & 590.0 \\
P20 & Critical photoperiod, $h$ & 11.7 & 11.3 \\
P2R & Photoperiod sensitivity, ${ }^{\circ}$ C-days & 50.0 & 150.0 \\
P5 & Grain filling phase, ${ }^{\circ}$ C-days & 400.0 & 450.0 \\
G1 & Potential spikelet number per g of main culm dry weight & 65.0 & 65.0 \\
G2 & Single grain weight, g & 0.021 & 0.022 \\
G3 & Tillering coefficient & 1.00 & 1.00 \\
G4 & Temperature tolerance coefficient & 1.00 & 1.00 \\
\hline
\end{tabular}

IR $36($ RMSEn $=0.14$ and D-index $=0.993)$ and Swarna $($ RMSEn $=0.22$ and D-index $=0.98)$ cultivars. The simulated anthesis and maturity days differed from their observed value up to 5 days and the difference between simulated and observed yield were within $8 \%$.

\subsubsection{Peanut}

The CROPGRO model was calibrated and validated for peanut cultivar 'AK 12-24' using dry season data of the years 2011 and 2012, respectively. During calibration, the RMSEn and Dindex between simulated and observed values of top biomass were 0.28 and 0.976 , respectively. The difference between observed and simulated days for anthesis, pod initiation, and maturity were within 5 days and for pod yield was about $10 \%$. The calibrated genotype
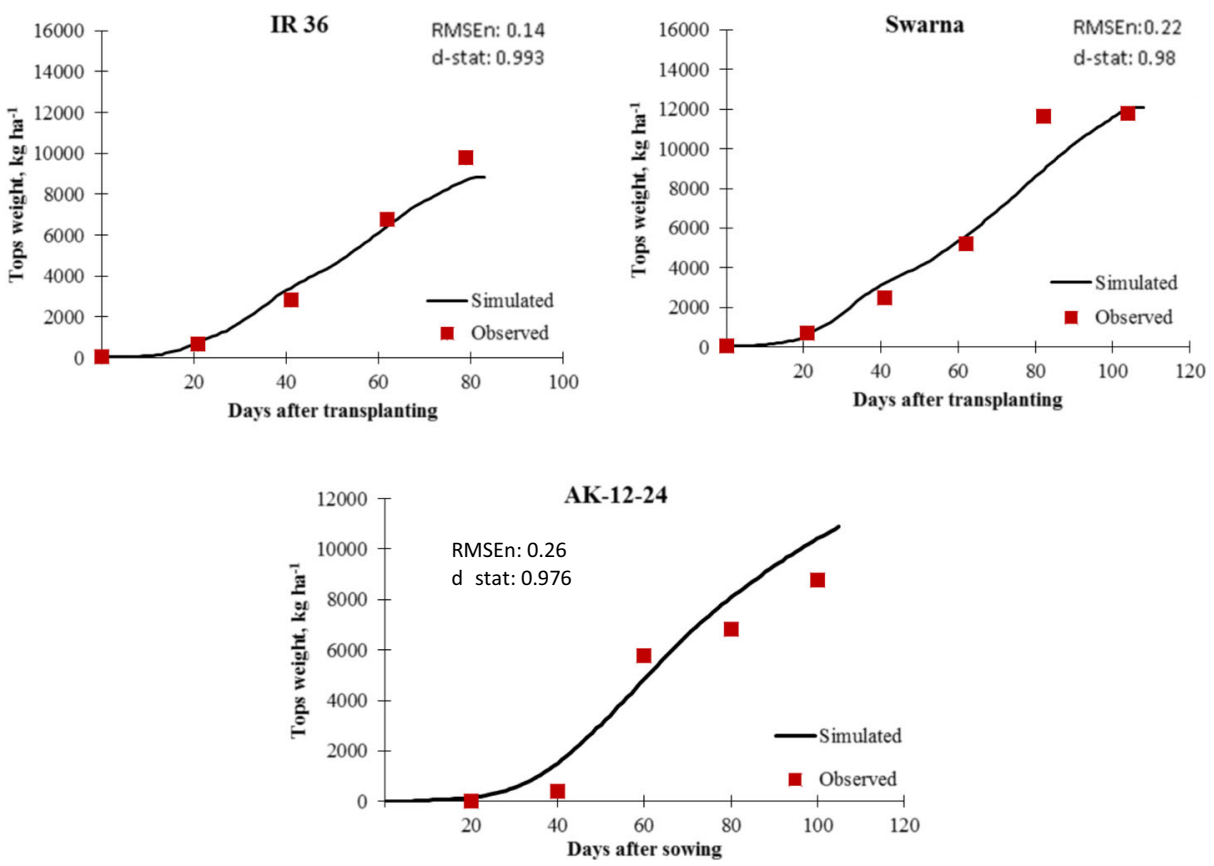

Fig. 2 Observed and simulated tops weight of rice cultivars (IR 36 and Swarna) and peanut cultivar (AK12-24) during model validation period at Kharagpur, India 
coefficients of peanut are given in Table 3. During testing (Fig. 2), there was close match between simulated and observed top biomass of peanut $($ RMSEn $=0.26$ and D-index $=0.976$ ). The difference between simulated and observed anthesis, pod initiation, and maturity were within 5 days and for pod yield was $<5 \%$.

The close match between observed and simulated values for biomass, phenology and yield for both crops during the testing process allows useful application of the model for simulation of crop performances under future climate change scenarios and evaluation of agroadaptations.

\subsection{Forecasting Crop Yield for Climate Change Scenarios}

\subsubsection{Rice}

The rice yield for both varieties (IR 36 and Swarna) was simulated for base period weather (1969-1999) and future periods of 2020 (2011-2040), 2050 (2041-2070), 2080 (2071-2100) under A2 and B2 scenarios (HadCM3 model) for all the selected locations in India. The grain yield of the medium (IR 36) as well as long duration cultivar (Swarna) declined from base period to the periods 2020, 2050 and 2080 under both scenarios (A2 and B2) of climate change at all locations (Fig. 3).

During the base period, simulated grain yield of both cultivars was maximum. The maximum grain yield was simulated at Vizianagaram/East Godavari followed by Cuttack and minimum grain yield at Kharagpur. The yield variability across the locations is due to the difference in the soil physico-chemical properties and climatic conditions of the various locations, as given in Table 1. Under A2 scenario, the grain yield of IR 36 declined by $0.34-4.96 \%, 2.96-10.18 \%$, and $7.34-12.30 \%$, during the 2020, 2050 and 2080, respectively across the locations, with maximum at Vizianagaram/East Godavari and minimum at Kharagpur. The rice growing season average temperature during 2020, 2050 and 2080 were $27.84,29.34$, and $30.69{ }^{\circ} \mathrm{C}$, respectively at Vizianagaram and $29.38,30.70$ and $32.35{ }^{\circ} \mathrm{C}$,

Table 3 Calibrated genotype coefficients of CROPGRO model for the peanut cultivar AK 12-24

\begin{tabular}{lll}
\hline Code & Definitions/Unit & Calibrated value \\
\hline CSDL & Critical Short Day Length, $\mathrm{h}$ & 11.84 \\
EM-FL & Time between plant emergence and flower appearance, photothermal days & 13.4 \\
FL-SH & Time between first flower and first pod, photothermal days & 8.0 \\
FL-SD & Time between first flower and first seed, photothermal days & 15.0 \\
SD-PM & Time between first seed and physiological maturity, photothermal days & 50.0 \\
FL-LF & Time between first flower and end of leaf expansion, photothermal days & 80.00 \\
LFMAX & Maximum leaf photosynthesis rate, $\mathrm{mg} \mathrm{CO}_{2} / \mathrm{m}^{2} \mathrm{~s}$ & 1.20 \\
SLAVR & Specific leaf area, cm ${ }^{2} / \mathrm{g}$ & 200 \\
SIZLF & Maximum size of full leaf, cm ${ }^{2}$ & 14 \\
XFRT & Maximum fraction of daily growth that is partitioned to seed + shell & 0.96 \\
WTPSD & Maximum weight per seed, $\mathrm{g}$ & 0.310 \\
SFDUR & Seed filling duration, photothermal days & 39 \\
SDPDV & Average seed number per pod & 1.61 \\
PODUR & Time required for cultivar to reach final pod load, photothermal days & 18.00 \\
\hline
\end{tabular}



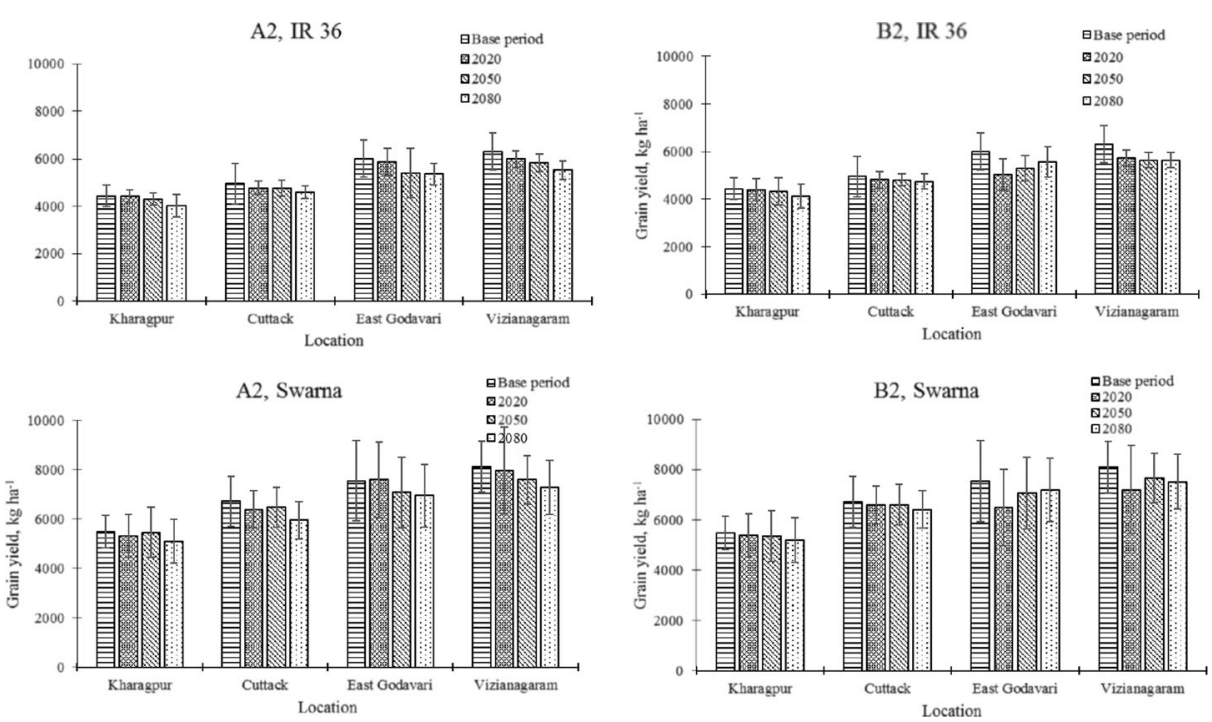

Fig. 3 Simulated grain yield of rice cultivars (IR 36 and Swarna) for base period and future years (2020, 2050 and 2080) under A2 and B2 climate change scenarios at different locations in India

respectively at Kharagpur. As compared to base period, the average rise in temperature during 2020, 2050 and 2080 periods was $0.72,2.22$, and $3.57^{\circ} \mathrm{C}$, respectively at Vizianagaram and $0.99,2.31$ and $3.96{ }^{\circ} \mathrm{C}$, respectively at Kharagpur. Though the temperature increase was lower at Vizianagaram as compared to Kharagpur, the yield decline was higher under the future climate scenarios. This is probably due to lower rainfall of amount $870 \mathrm{~mm}$ occurring at Vizianagaram as compared to that of Kharagpur $(\approx 1140 \mathrm{~mm})$ under the climate change scenarios. Rice crop generally requires $1200-1400 \mathrm{~mm}$ rainfall for normal production under rainfed ecosystem (http://www.rkmp.co.in/content/climatic-and-soil-requirements). Hence, the high rice yield decline at Vizianagaram was mostly attributed to low rainfall under future climate scenarios.

The rice grain yield was significantly and negatively correlated with maximum $(r=-0.545)$ and minimum $(r=-0.592)$ temperature at $p=0.01$ over the locations. The higher correlation coefficient between grain yield and minimum temperature confirms the results of the study by Peng et al. (2004). They stated that the effect of night temperature was significant in influencing rice yield. Similarly, the maximum temperature of more than $35{ }^{\circ} \mathrm{C}$ was critical temperature during flowering (Yoshida 1981). A short period (1-3 days) exposure to high temperature during flowering period can significantly reduce seed set, and thereby, crop yield in rice (Jagadish et al. 2008). The loss of yield is due to heat induced spikelet sterility or higher crop respiration rate during grain filling period, which reduces grain filling capacity and thereby grain yield (Fitzgerald and Resurreccion 2009). In our simulation study, the maximum temperature for various locations during grain filling period (flowering to maturity) varied from 33 to $36{ }^{\circ} \mathrm{C}$ for different climate change scenarios, which was higher by 3.9 to $4.3{ }^{\circ} \mathrm{C}$ over base period, hence depicted a decline in grain yield by 8 to $12 \%$.

The results for cultivar Swarna were also in line with the results for IR 36 cultivar. However, the yield of Swarna cultivar was higher than that of IR 36 owing to its genetic characteristics. The Swarna cultivar is a longer duration and high yielding as compared to IR 36. The percentage decline in yield of Swarna under future climate scenarios was lower than 
that of IR 36. Further, among the climate change scenarios, the increment in temperature was less in B2 scenario as compared to A2 scenario (Fig. 1), which may have resulted in marginally lower yield decline in B2 scenario for both varieties.

\subsubsection{Peanut}

The yield of Peanut (var. AK 12-24) was simulated for base period weather (1969-99) and future periods of 2020 (2011-2040), 2050 (2041-2070) and 2080 (2071-2100) under A2 and B2 scenarios (HadCM3 model) for all the selected locations in India. In the base period, maximum peanut yield was simulated from Vizianagaram/East Godavari followed by Cuttack and minimum yield from Kharagpur. The yield of the peanut declined from the base period (1969-1999) to 2020 (2011-2040), 2050 (2041-2070) and 2080 (2071-2100) periods under both scenarios (A2 and B2) of climate change at all the locations (Fig. 4). Under A2 scenario, the change in yield of peanut was +5.3 to $-5.06 \%,-7.2$ to $-17.48 \%$, and -38.7 to $-46.7 \%$
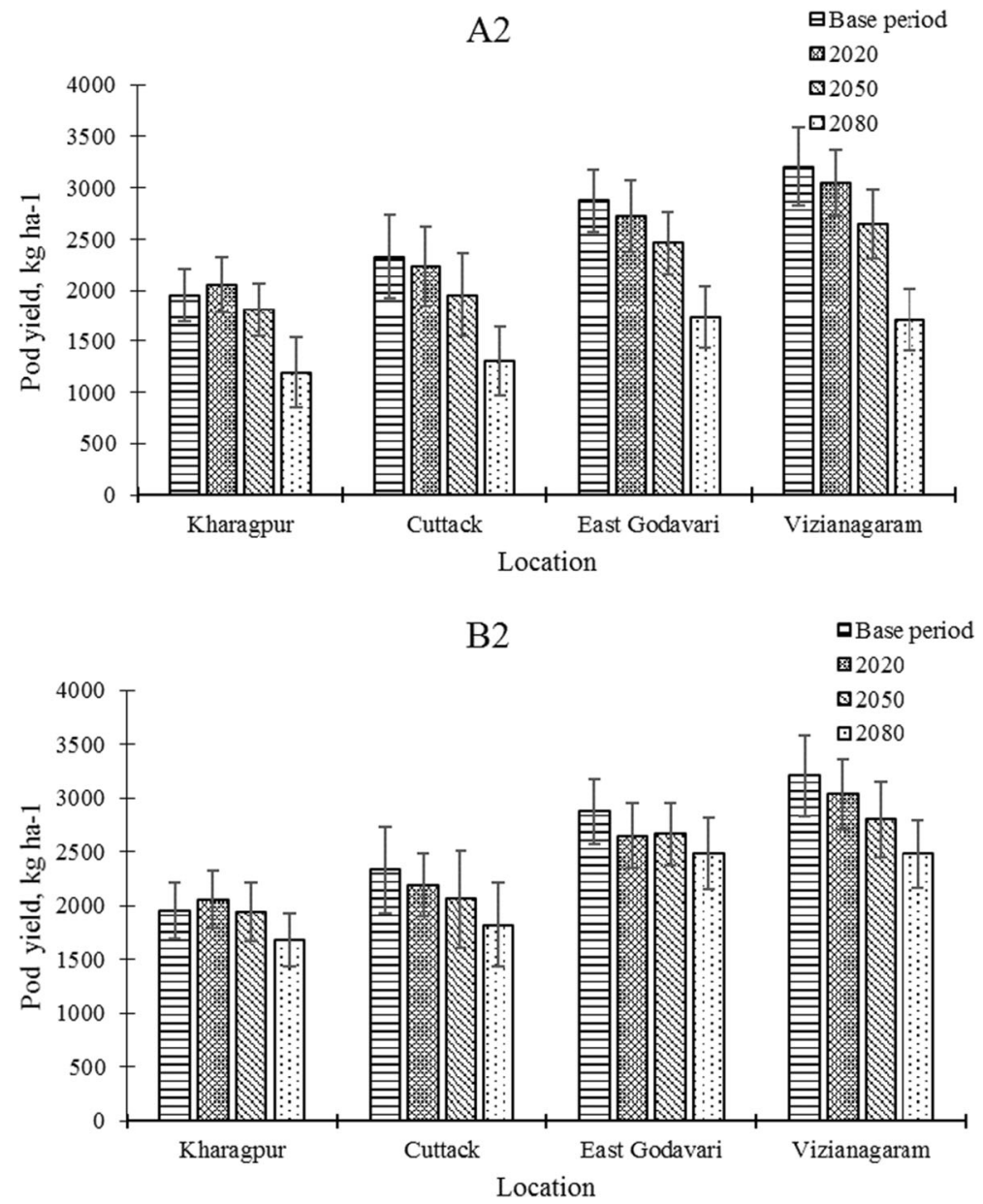

Fig. 4 Simulated peanut pod yield for base period and future years (2020, 2050 and 2080) under A2 and B2 climate change scenarios at different locations in India 
during the 2020, 2050 and 2080, respectively across the locations, with maximum decline at Vizianagaram/East Godavari and minimum at Kharagpur.

Under the A2 scenario, during crop growth period, the average temperature at Vizianagaram was $29.34,30.61$ and $32.65{ }^{\circ} \mathrm{C}$ in 2020,2050 and 2080 , respectively which was higher by $1.13,2.40$, and $4.44{ }^{\circ} \mathrm{C}$, respectively, as compared to base period temperature. Similarly, at Kharagpur the average temperature was 28.86, 30.09 and $32.16{ }^{\circ} \mathrm{C}$ for the 2020,2050 and 2080 , respectively, which were closer to that of Vizianagaram, but these were higher by $0.73,1.96$ and $4.02{ }^{\circ} \mathrm{C}$ for the corresponding years over the base period. The higher increase in temperature at Vizianagaram as compared to Kharagpur under future climate scenarios, possibly simulated higher decline in peanut yield in the former location.

The mean optimal air temperature during vegetative growth of peanut varies between 25 and $30{ }^{\circ} \mathrm{C}$, which is higher than the optimum range $\left(22\right.$ to $24{ }^{\circ} \mathrm{C}$ ) for reproductive growth (Prasad et al. 2003). Exposure to the air and soil temperatures above the optimum level even for shorter period can lead to significant yield loss in peanut. In our simulation study, the average temperature during reproductive growth of peanut was found to be 25.8, 26.2, 26.5 and $26.1{ }^{\circ} \mathrm{C}$ during base period at Kharagpur, Cuttack, East Godavari, and Vizianagaram, respectively. The reproductive phase temperatures for the corresponding locations were higher by $1.3,0.8,0.8$, and $1.0^{\circ} \mathrm{C}$ for $2020 ; 2.5,1.9,2.0$ and $2.4^{\circ} \mathrm{C}$ for 2050 , and $4.0,3.3,3.4$ and $3.9^{\circ} \mathrm{C}$ for 2080 scenarios, respectively. Increasing temperature during reproductive stage of peanut in future climate at all the locations resulted in significant decline in peanut yield.

The critical temperature for the pod set was found to be $33{ }^{\circ} \mathrm{C}$, above which the pod set was significantly affected. Even 1 day exposure to temperature $\geq 39{ }^{\circ} \mathrm{C}$ significantly reduced pod set compared to the control at $28{ }^{\circ} \mathrm{C}$ (Prasad et al. 2001). High temperature was responsible for pollen sterility and poor pollen tube growth. In our study, the average maximum temperature during flowering period for the base period was 31.9 and $31.6{ }^{\circ} \mathrm{C}$ at Vizianagaram and Kharagpur, respectively, which increased to 36.7 and $37.2{ }^{\circ} \mathrm{C}$ in 2080 scenario simulating yield reduction of 46 and $38 \%$, respectively (Fig. 10).

The correlation between average temperature and pod yield was negative and significant $(r=-0.503$ at $p=0.01)$. This was in agreement with Prasad et al. (2003), who reported decrease in pollen viability with increase in temperature $\left(32 / 22{ }^{\circ} \mathrm{C}\right.$ to $\left.44 / 34{ }^{\circ} \mathrm{C}\right)$ for both ambient $(350 \mathrm{ppm})$ and elevated $\mathrm{CO}_{2}(700 \mathrm{ppm})$. They also showed that decrease in seed yield occurs for elevated $\mathrm{CO}_{2}$ peanut plants at temperatures $\geq 36{ }^{\circ} \mathrm{C}$ despite greater photosynthesis and biomass accumulation. Effect of high air temperature $\left(38 / 22^{\circ} \mathrm{C}\right.$ vs $\left.28 / 22{ }^{\circ} \mathrm{C}\right)$ affected the fruit set significantly but did not affect the number of flowers produced. Pilumwong et al. (2007) reported that above ground biomass of groundnut was increased by elevated $\mathrm{CO}_{2}$ irrespective of temperature regime $\left(25 / 15^{\circ} \mathrm{C}\right.$ vs $\left.35 / 25^{\circ} \mathrm{C}\right)$. In our study also, the above ground biomass was found to be increasing from base period to 2020, 2050 and 2080 for all locations. The highest above ground biomass at 2080 scenario with 540 ppm $\mathrm{CO}_{2}$ level indicates that the high temperature regime observed during 2080 scenario was still within optimum range for biomass production of peanut. The study showed that at high temperature, the dry matter production was increased but the yield of peanut was significantly affected. Similar results were reported by Bannayan et al. (2009), which revealed that the above ground biomass/total biomass production in peanut increases with increase in $\mathrm{CO}_{2}$ level independent of temperature regime. 


\subsection{Yield of Rice-Peanut Cropping System}

The yield of both cropping systems (MP and LP) was simulated for base period weather (1969-99) and future weather of 2020 (2011-2040), 2050 (2041-2070), 2080 (2071-2100) of A2 and B2 scenarios (HadCM3 model) at all the selected locations in India. The rice equivalent yield of cropping system was calculated using Eq. (3). The percentage change in the system yield under the future scenarios was calculated by comparing with the system yield during base period as given in Eq. (4). The system yield for both the cropping systems declined from the base period to 2020 (2011-2040), 2050 (2041-2070) and 2080 (2071-2100) periods under both scenarios (A2 and B2) of climate change at all locations (Figs. 5 and 6).

Under A2 scenario, the rice equivalent yield of MP cropping system varied from +3.95 to $-5.4 \%,-3.45$ to $-12.39 \%$ and -25.4 to $-32.1 \%$ during the years 2020 (2011-2040), 2050 (2041-2070) and 2080 (2071-2100), respectively, as compared to base period across the locations, with maximum reduction at Vizianagaram/East Godavari and minimum at Kharagpur. The decline in system yield was increased with decreasing latitude, from Kharagpur $\left(22^{\circ} 25^{\prime} \mathrm{N}\right)$ to Vizianagaram $\left(18^{\circ} 12^{\prime} \mathrm{N}\right)$. This was due to lower rainfall during rice growing season (wet season) and higher temperature during peanut growing season (dry season) in lower latitude (Vizianagaram) as
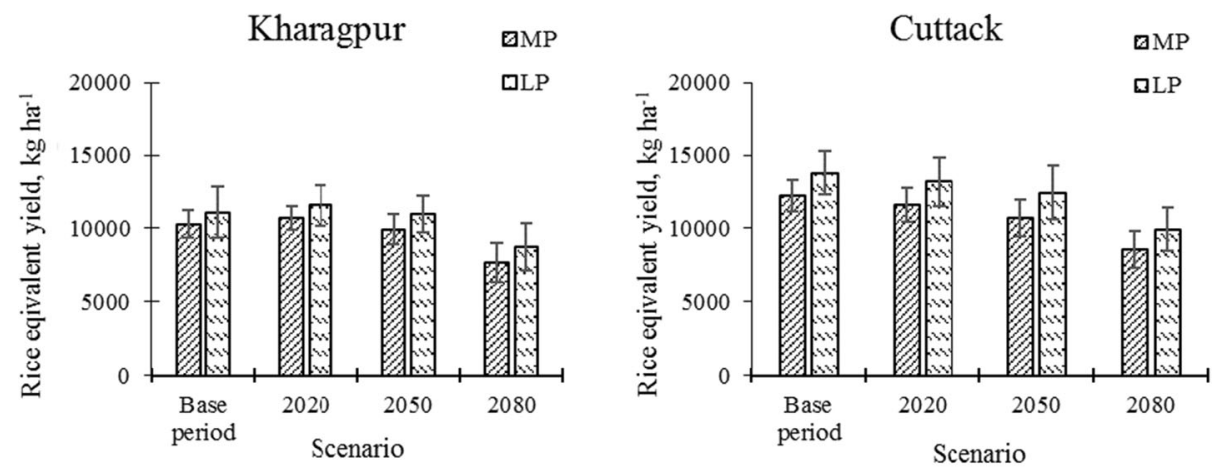

East Godavari
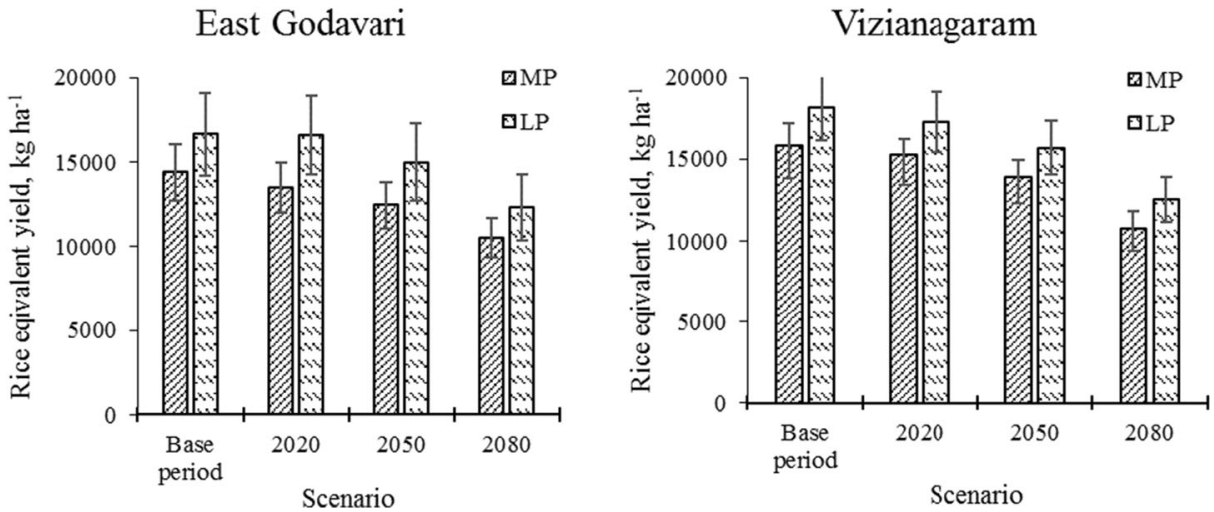

Fig. 5 Rice equivalent yield of rice-peanut cropping systems in medium- (MP) and long-duration (LP) rice cultivar for base period and future years (2020, 2050 and 2080) under A2 climate change scenarios at different locations (Kharagpur, Cuttack, East Godavari and Vizianagaram) in India 

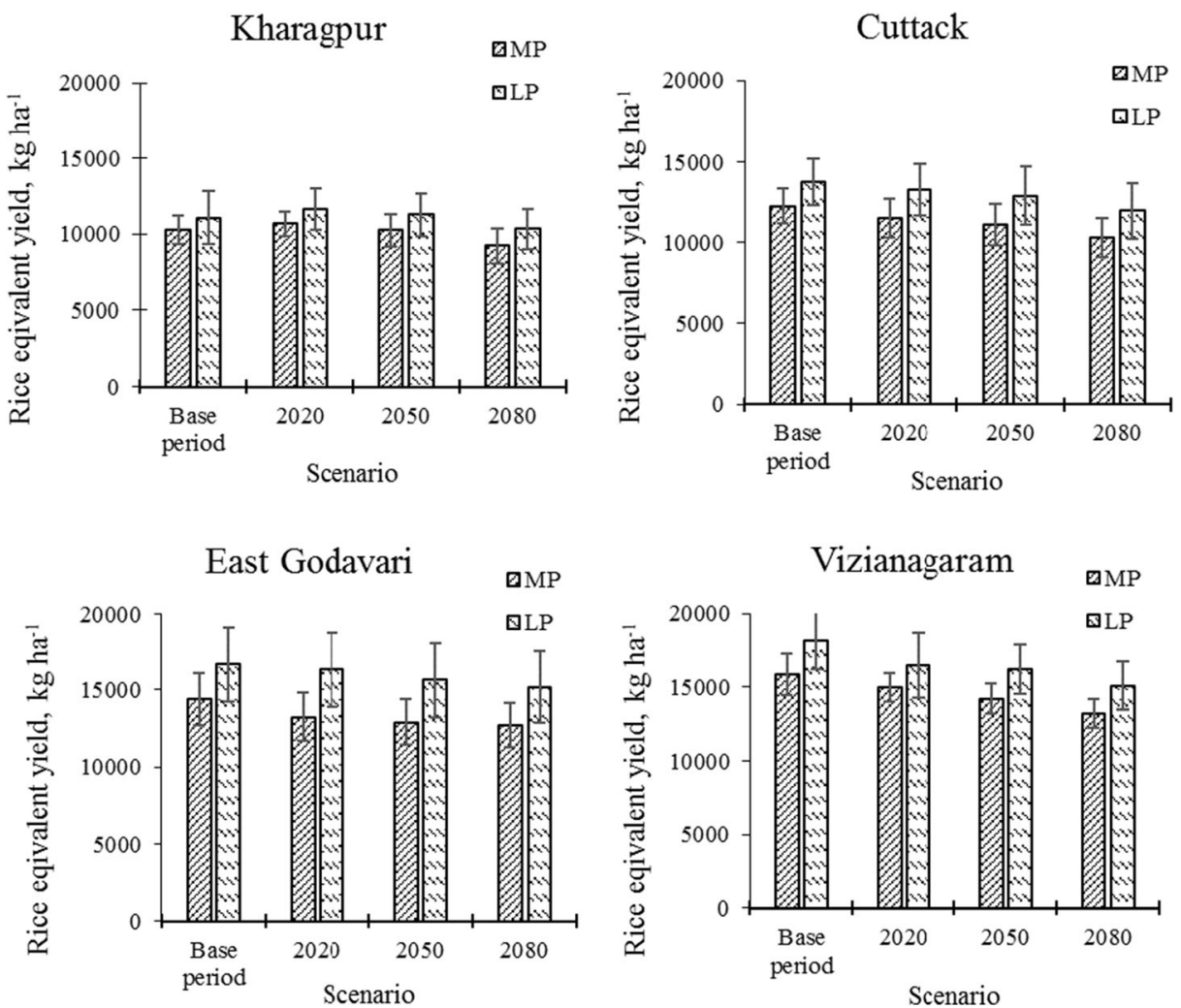

Fig. 6 Rice equivalent yield of rice-peanut cropping systems in medium- (MP) and long-duration (LP) rice cultivar for base period and future years (2020, 2050 and 2080) under B2 climate change scenarios at different locations (Kharagpur, Cuttack, East Godavari and Vizianagaram) in India

compared to higher latitude (Kharagpur) under the future climate scenarios. Under B2 scenario, the percentage change in yield was lower compared to A2 scenario at all locations for the future climate scenarios. At Kharagpur only, the yield increased marginally in 2020, but it declined thereafter. Similar trends of yield change for future climate scenarios were simulated for LP cropping system at all locations where the yield variation was lower as compared to that of MP system.

\subsection{Evaluation of Adaptation Measures}

Planting time and varietal changes in rice and sowing time adjustment in peanut were evaluated as an adaptation options to climate change in the rice-peanut cropping system. The normal sowing time for the nursery of rice in kharif season in West Bengal is MayJune. The nursery sown in June is transplanted at the age of 25-30 days. Therefore, transplanting date ' 15 July' was considered as current (normal) transplanting date for rice (Adhikari et al. 2010) and the sowing time '9 February' for peanut were considered as the normal planting time ( $15 \mathrm{July} / 9$ February) for the rice-peanut cropping system. The result stated increase in the yield in 2020 (2011-2040) under both climate scenarios (A2 and B2), as compared to the base period, with advancement of planting time to 1 June/26 
Dec and 15 June/10 January from the normal planting (15 July/9 February) at all locations in MP as well as LP cropping system (Figs. 7 and 8). In 2050 (2041-2070) and 2080 (2071-2100), the advanced planting continued to show the positive response for yield improvement at Kharagpur and Cuttack, whereas at East Godavari and Vizianagaram, the yield declined for all the planting time during 2050 and 2080. However, the decline in yield was lower in advanced planting as compared to delayed planting. The amount of rainfall received with 1 June planting date was higher than the current planting date of 15 July, whereas with delayed planting date (1 August) the amount of rainfall received during crop growing period was lowest. The delayed planting (31 July/24 February) had maximum grain yield reduction in future climate scenarios at all the locations for both cropping systems. The yield of LP cropping system was higher than MP cropping system for all climate scenarios at all locations (Fig. 8).

In our simulation study, it was observed that delayed rice planting after 15 July exposes the grain filling period to high temperature $\left(>30{ }^{\circ} \mathrm{C}\right)$ during 2050 and 2080 at all locations, which leads to spikelet sterility, and hence, higher reduction in the grain yield. Our results were in confirmation with Krishnan et al. (2007), who reported that higher maximum temperature $\left(>30^{\circ} \mathrm{C}\right)$ during flowering period across the location was the major reason of yield reduction in rice. Moreover, with delayed planting, the rice crop receives very low amount (611 to $816 \mathrm{~mm}$ ) of rainfall as compared to early planting (1208 to $1391 \mathrm{~mm}$ ) across the locations in future climate scenarios that causes grain yield reduction as the rice is grown under rainfed ecosystem. The amount of rainfall received during crop period for different planting dates at Kharagpur is shown in Fig. 9. Thus, adjustment in sowing date was one of the adaptation options which can be implemented at field level to reduce the detrimental effect on yield production. Adoption of temperature tolerance to spikelet sterility increased yield, which confirms effect of temperature
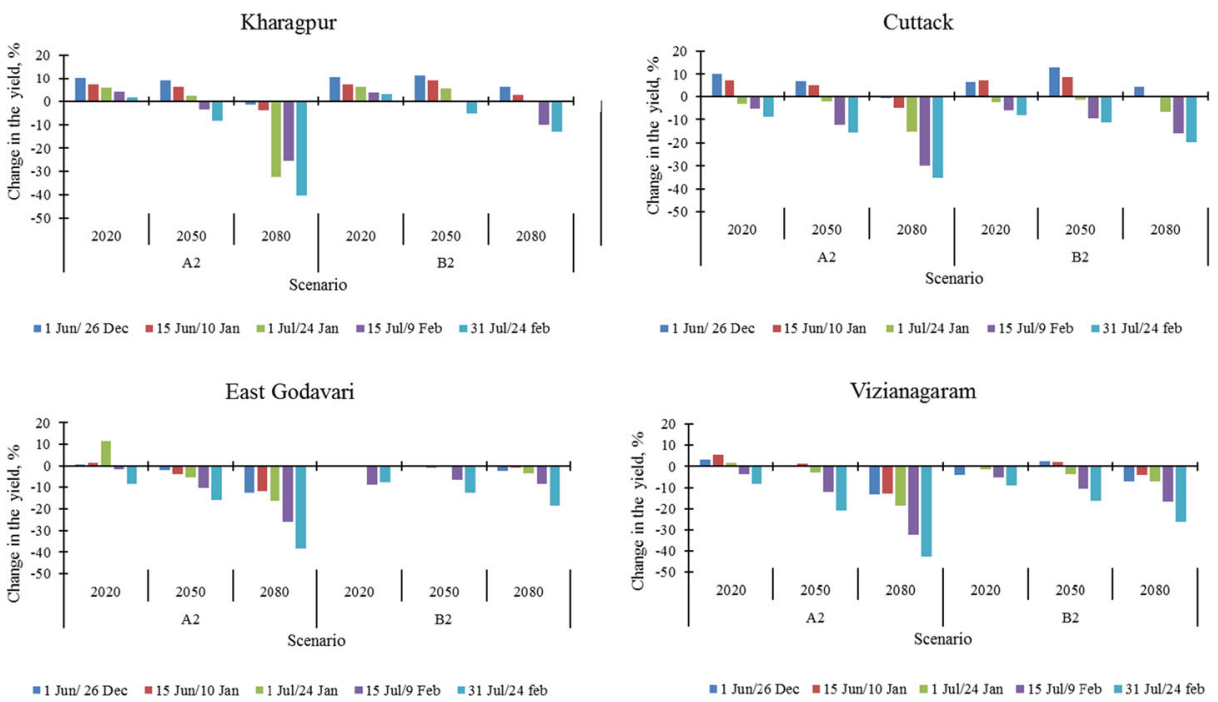

Fig. 7 Change in rice equivalent yield of rice-peanut cropping systems with medium duration cultivar (MP) for future years (2020, 2050 and 2080) under A2 and B2 climate change scenarios for different planting time as compared to base period with normal planting (15 Jul./9Feb) at different locations (Kharagpur, Cuttack, East Godavari and Vizianagaram) in India 

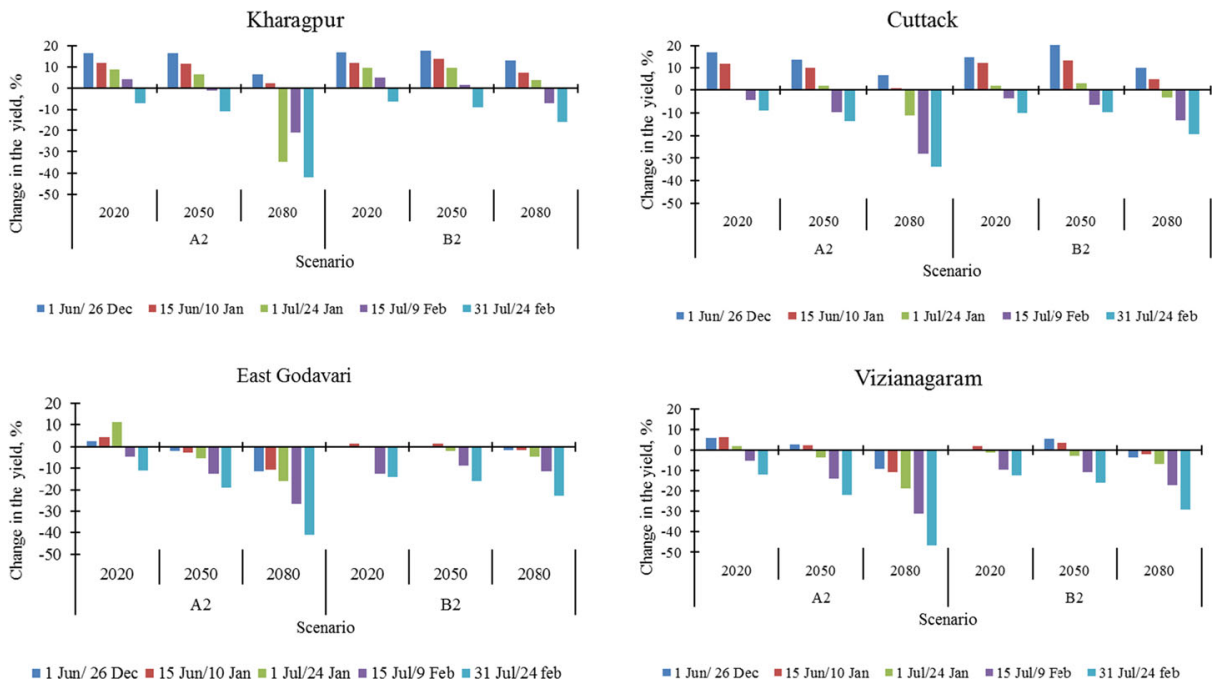

| $1 \mathrm{Jun} / 26 \mathrm{Dec}=15 \mathrm{Jun} / 10 \mathrm{Jan}=1 \mathrm{Jul} / 24 \mathrm{Jan}=15 \mathrm{Jul} / 9 \mathrm{Feb}=31 \mathrm{Jul} / 24 \mathrm{feb}$

=1 Jun/ $26 \mathrm{Dec}=15 \mathrm{Jun} / 10 \mathrm{Jan}=1 \mathrm{Jul} / 24 \mathrm{Jan}=15 \mathrm{Jul} / 9 \mathrm{Feb}=31 \mathrm{Ju} / 24 \mathrm{feb}$

Fig. 8 Change in rice equivalent yield of rice-peanut cropping systems with long duration cultivar (LP) for future years (2020, 2050 and 2080) under A2 and B2 climate change scenarios for different planting time as compared to base period with normal planting (15 Jul/9Feb) at different locations (Kharagpur, Cuttack, East Godavari and Vizianagaram) in India

on rice yield. Similar results about sensitivity of spikelet sterility to flowering were reported by many researchers (Yoshida 1981; Krishnan and Surya Rao 2005; Jagadish et al. 2008). Similarly for peanut, high temperature during flowering can be avoided by advancing the sowing time. Average temperature during 1st pod to maturity period at Kharagpur is shown in Fig. 10. Flowering and pre-flowering are the most sensitive stages to temperature in peanut (Prasad et al. 1999a, b). High temperature stress during flowering lead to poor fertilization, affects pollen germination and pollen tube and hence pod yield (Prasad et al. 2003; Prasad et al. 2011).

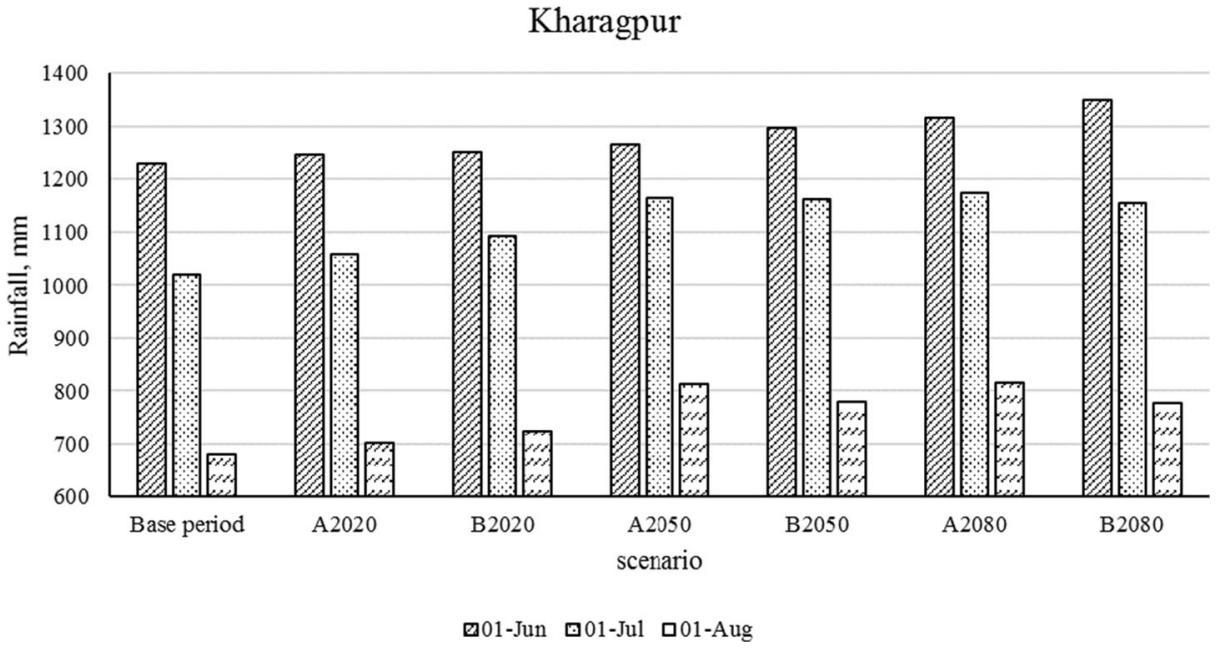

Fig. 9 Amount of rainfall received during rice crop period under different climate change scenarios and planting dates at Kharagpur location 


\section{Kharagpur}

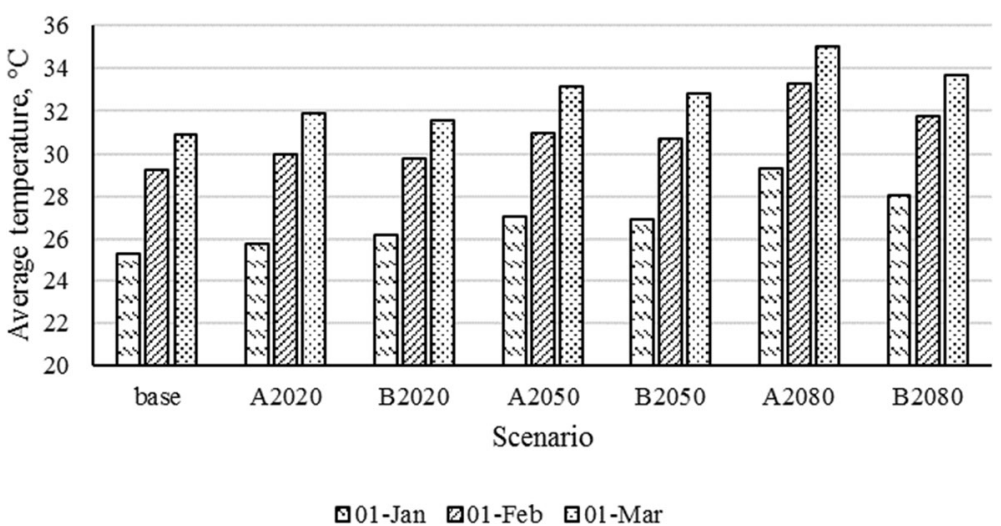

Fig. 10 Average temperature during 1st pod to maturity of peanut under different climate change scenarios and sowing dates at Kharagpur

\section{Conclusions}

The variability in the yield of the rice-peanut cropping system among different locations in India was due to the differences in native soil properties and basic weather parameters. The yield of the cropping system is expected to decline at all the locations under future climate scenarios with varying rainfall and rising temperature. The yield declined with locations from higher latitude to lower latitude for the base period as well as for the future periods. However, the effect of climate change could be minimized or even could be favorable in crop yield improvement through change of planting time under rainfed ecosystem in India. Earlier planting time resulted in increased yield of rice-peanut system under future climate scenarios at higher latitudes. This was due to increased amount of precipitation received by the rainfed rice during the growing season and favorable temperature during the critical growth phase (flowering to maturity) of both rice and peanut in early planting as compared to delayed planting. The early planting was also effective at lower latitude in minimizing the adverse impact of climate change on yield of both crops in the cropping system. Analyzing the varietal adaptation among the rice cultivars, the long-duration 'Swarna' has longer vegetative growth and later reproductive allows the crop to mature in cooler temperature, hence less vulnerable to rising temperature as compared to the medium duration 'IR 36'. Hence, the rice cultivar 'Swarna' with advanced planting of both rice and peanut is expected to combat the adverse impact of climate change on the rice-peanut cropping system.

Acknowledgments This work is supported by Regional climate change: Integrated Analysis for Impact, Mitigation and Sustainability (IAIMS), C-MMACS, CSIR, Bangalore, India.

\section{References}

Adhikari B, Bag MK, Bhowmick MK, Kundu C (2010) Rice in West Bengal. status paper on rice in West Bengal: $1-88$ 
Aggarwal PK, Banerjee B, Daryaei MG, Bhatia A, Bala A, Rani S, Chander S, Pathak H, Kalra N (2006a) InfoCrop: a dynamic simulation model for the assessment of crop yields, losses due to pests, and environmental impact of agro-ecosystems in tropical environments. II. Performance of the model. Agric Syst 89(1):47-67

Aggarwal PK, Kalra N, Chander S, Pathak H (2006b) InfoCrop: a dynamic simulation model for the assessment of crop yields, losses due to pests, and environmental impact of agro-ecosystems in tropical environments I. Model description. Agric Syst 89:1-25

Aggarwal PK, Hebbar KB, Venugopalan MV, Rani S, Bala A, Biswal A, Wani SP (2008) Quantification of yield gaps in rain-fed rice, wheat, cotton and mustard in India. Global Theme on Agro-ecosystems Report no. 43. Patancheru 502324, Andhra Pradesh, India: International Crops Research Institute for the Semi-Arid Tropics

Ainsworth EA, Long SP (2005) What have we learned from 15 years of free-air $\mathrm{CO}_{2}$ enrichment (FACE): a meta-analytic review of the responses of photosynthesis, canopy properties and plant production to rising $\mathrm{CO}_{2}$ ? New Phytol 165:351-372

Bannayan M, TojoSoler CM, Garcia AGY, Guerra LC, Hoogenboom G (2009) Interactive effects of elevated $\left[\mathrm{CO}_{2}\right]$ and temperature on growth and development of a short- and long-season peanut cultivar. Clim Chang 93(3-4):389-406

Bouman BAM, Van Keulen H, Van Laar HH, Rabbinge R (1996) The 'School of de Wit' crop growth simulation models: pedigree and historical overview. Agric Syst 52:171-198

FAO (Food and Agriculture Organization of the United Nations) (2009) Electronic on-line database. Online at http://www.faostat.fao.org

Fitzgerald MA, Resurreccion AP (2009) Maintaining the yield of edible rice in a warming world. Funct Plant Biol 36:1037-1045

Gordon C, Cooper C, Senior CA, Banks HT, Gregory JM, Johns TC, Mitchell JFB, Wood RA (2000) The simulation of SST, sea ice extents and ocean heat transports in a version of the Hadley Centre coupled model without flux adjustments. Clim Dyn 16:147-168

IPCC (2013) Summary for policymakers. In: Stocker TF, Qin D, Plattner GK, Tignor M, Allen SK, Boschung J, Nauels A, Xia Y, Bex V, Midgley PM (eds) Climate change 2013: the physical science basis. Contribution of Working Group I to the Fifth Assessment Report of the Intergovernmental Panel on Climate Change. Cambridge University Press, Cambridge

Jagadish SVK, Craufurd PQ, Wheeler TR (2008) Phenotyping parents of mapping populations of rice (Oryza sativa L.) for heat tolerance during anthesis. Crop Sci 48:1140-1146

Jones JW, Hoogenboom G, Porter CH, Boote KJ, Batchelor WD, Hunt LA, Wilkens PW, Singh U, Gijsman AJ, Ritchie JT (2003) The DSSAT cropping system model. Eur J Agron 18:235-265

Kim HY, Lieffering M, Kobayashi K, Okada M, Miura S (2003) Seasonal change in the effects of elevated $\mathrm{CO}_{2}$ on rice at three levels of nitrogen supply: a free airCO $\mathrm{O}_{2}$ enrichment (FACE) experiment. Global Change Biol. 9:826-837

Krishnan P, Surya Rao AV (2005) Effects of genotypic and environmental on seed yield and quality of rice. J Agric Sci 143:283-292

Krishnan P, Swain DK, Bhaskar BC, Nayak SK, Dash RN (2007) Impact of elevated $\mathrm{CO}_{2}$ and temperature on rice yield and methods of adaptations as evaluated by crop simulation studies. Agric Ecosyst Environ 122: 233-242

Kropff, MJ, Van Laar HH, Matthews RB (1994) ORYZA1, an eco-physiological model for irrigated rice production. In: SARP Research Proceedings, AB-DLO, Wageningen, The Netherlands, p. 110

Madan P, Jagadish SVK, Craufurd PQ, Fitzgerald M, Lafarge T, Wheeler TR (2012) Effect of elevated $\mathrm{CO}_{2}$ and high temperature on seed-set and grain quality of rice. J Exp Bot 63:3843-3852

Mall RK, Singh R, Gupta A, Srinivasan G, Rathore L (2006) Impact of climate change on Indian agriculture: a review. Climate Change 78(2):445-478

Mishra A, Singh R, Raghuwanshi NS, Chatterjee C, Froebrich J (2013) Spatial variability of climate change impacts on yield of rice and wheat in the Indian Ganga basin. Sci Total Environ 468-469:S132-S138

Ogden E, Innes JL (2008) Climate change adaptation and regional forest planning in southern Yukon, Canada. Mit. Ad. Strat. Global Change 13:833-861

Parry ML, Rosenzweig C, Iglesias A, Livermore M, Fischer G (2004) Effects of climate change on global food production under SRES emissions and socio-economic scenarios. Global Environ Change 14:53-67

Pathak H, Ladha JK, Aggarwal PK, Peng S, Das S, Singh Y, Singh B, Kamra SK, Mishra B, Sastri ASRAS, Aggarwal HP, Das DK, Gupta RK (2003) Trends of climatic potential and on-farm yields of rice and wheat in the Indo-Gangetic Plains. Field Crop Res 80(3):223-234 
Peng SB, Huang JL, Sheehy JE, Laza RC, Visperas RM, Zhong X, Centeno GS, Khush GS, Cassaman KG (2004) Rice yield decline with higher night temperature from global warming. Proc Natl Acad Sci USA 101: 9971-9975

Pilumwong J, Senthonga C, Srichuwongb S, Ingram KT (2007) Effects of temperature and elevated $\mathrm{CO}_{2}$ on shoot and root growth of peanut (Arachis hypogaea L.) grown in controlled environment chambers. Sci Asia 33:79-87

Pope VD, Gallani ML, Rowntree PR, Stratton RA (2000) The impact of new physical parameterizations in the Hadley Centre climate model: HadAM3. Clim Dyn 16:123-146

Prasad PVV, Craufurd PQ, Summerfield RJ (1999a) Sensitivity of peanut to timing of heat stress during reproductive development. Crop Sci 39:1352-1357

Prasad PVV, Craufurd PQ, Summerfield RJ (1999b) Fruit number in relation to pollen production and viability in groundnut exposed to short episodes of heat stress. Ann Bot 84:381-386

Prasad PVV, Craufurd PQ, Kakani VG, Wheeler TR, Boote KJ (2001) Influence of high temperature during preand post-anthesis stages of floral development on fruit-set and pollen germination in peanut. Aust J Plant Physiol 28:233-240

Prasad PVV, Boote KJ, Allen Jr LH, Thomas JMG (2003) Super-optimal temperatures are detrimental to peanut (Arachis hypogaea L.) reproductive processes and yield under both ambient and elevated carbon dioxide. Glob Chang Biol 9:1775-1787

Prasad PVV, Boote KJ, Allen Jr LH (2011) Longevity and temperature response of pollen as affected by elevated growth temperature and carbon dioxide in peanut and grain sorghum. Environ Exp Bot 70(1):51-57

Razzaque MA, Haque MM, Khaliq QA, Soliman ARM, Hamid A (2011) Effects of $\mathrm{CO}_{2}$ and nitrogen levels on yield and yield attributes of rice cultivars. Bangladesh J Agric Res 36:213-221

Ritchie JT, Singh U, Godwin DC, Bowen WT (1998) Cereal growth, development and yield. In: Tsuji GY, Hoogenboom G, Thornton PK (eds) Understanding options for agricultural production. Kluwer Academic Publishers, Dordrecht, pp. 79-98

Rosenzweig C, Hillel D (1998) Climate change and the global harvest. In: In PBD: 323. Oxford University Press, NY

Satapathy SS, Swain DK, Herath S (2014) Field experiments and simulation to evaluate rice cultivar adaptation to elevated carbon dioxide and temperature in sub-tropical India. Eur J Agron 54:2133

Sharma KD (2011) Rain-fed agriculture could meet the challenges of food security in India. Curr Sci 100(11): $1615-1616$

Sheehy JE, Mitchell PL, Ferrer AB (2006) Decline in rice grain yields with temperature: models and correlations can give different estimates. Field Crop Res 98:151-156

Silva CSD, Weatherhead EK, Knox JW, Rodriguez-Diaz JA (2007) Predicting the impacts of climate change-a case study of paddy irrigation water requirements in Sri Lanka. Agric Water Manag 93: $19-29$

Subash N, Ram Mohan HS (2012) Evaluation of the impact of climatic trends and variability in rice-wheat system productivity using cropping system model DSSAT over the Indo-Gangetic Plains of India. Agric For Meteorol 164:71-81

Swain DK, Thomas D (2010) Climate change impact assessment and evaluation of agro-adaptation measures for rice production in Eastern India. J Environ Inform 16:94-101

Trnka M, Dubrovsky M, Semeradova D, Zalud Z (2004) Projections of uncertain-ties in climate change scenarios into expected winter wheat yields. Theor Appl Climatol 77:229-249

Vittal KPR, Sinha PK, Ravindra CG, Maruthi SGR, Srijaya T, Ramakrishna YS, et al (2004) Eds. District wise promising technologies for rainfed rice based production system in India. All India Co-ordinated Research Project for Dryland Agriculture, Central Research Institute for Dryland Agriculture, Indian Council of Agricultural Research, Hyderabad 500059, $114 \mathrm{pp}$

Willmott CJ, Ackleson SG, Davis RE, Feddema JJ, Klink KM, Legates DR, et al. (1985) Statistics for the evaluation and comparison of models. J Geophys Res 90:8995-9005

Xiong W, Matthews R, Holman I, Lin E, Xu Y (2007) Modelling China's potential maize production at regional scale under climate change. Clim Chang 85:433-451

Yoshida S (1981) Fundamentals of rice crop science. International Rice Research Institute, Los Baños, 269 pp 